\title{
White and Green Teas (Camellia sinensis var. sinensis): Variation in Phenolic, Methylxanthine, and Antioxidant Profiles
}

\section{Authors: Uchenna J. Unachukwu, Selena Ahmed, Adam Kavalier, James T. Lyles, and Edward J. Kennelly}

This is the peer reviewed version of the following article: see citation below, which has been published in final form at https://doi.org/10.1111/j.1750-3841.2010.01705.x. This article may be used for non-commercial purposes in accordance with Wiley Terms and Conditions for SelfArchiving.

Unachukwu, Uchenna J., Selena Ahmed, Adam Kavalier, James T. Lyles, and Edward J. Kennelly. "White and Green Teas (Camellia Sinensis Var. Sinensis): Variation in Phenolic, Methylxanthine, and Antioxidant Profiles." Journal of Food Science 75, no. 6 (August 2010): C541-C548. doi:10.1111/j.1750-3841.2010.01705.x. 


\title{
White and Green Teas (Camellia sinensis var. sinensis): Variation in Phenolic, Methylxanthine, and Antioxidant Profiles
}

\author{
Uchenna J. Unachukwu, Selena Ahmed, Adam Kavalier, James T. Lyles, and Edward J. Kennelly
}

\begin{abstract}
Recent investigations have associated white teas with anti-carcinogenic, immune-boosting, and antioxidative properties that may impact human health in a manner comparable to green teas. An in-depth chemical analysis of white tea types was conducted to quantify polyphenols and antioxidant potential of 8 commercially available white teas, and compare them to green tea. Extraction and HPLC protocols were optimized and validated for the quantification of 9 phenolic and 3 methylxanthine compounds to examine inter- and intra-variation in white and green tea types and subtypes. A sampling strategy was devised to assess various subtypes procured from different commercial sources. Variation in antioxidant activity and total phenolic content (TPC) of both tea types was further assessed by the 1-1diphenyl-2-picrylhydrazyl (DPPH) and Folin-Ciocalteau (F-C) assays, respectively. Total catechin content (TCC) for white teas ranged widely from 14.40 to $369.60 \mathrm{mg} / \mathrm{g}$ of dry plant material for water extracts and 47.16 to $163.94 \mathrm{mg} / \mathrm{g}$ for methanol extracts. TCC for green teas also ranged more than 10-fold, from 21.38 to $228.20 \mathrm{mg} / \mathrm{g}$ of dry plant material for water extracts and 32.23 to $141.24 \mathrm{mg} / \mathrm{g}$ for methanol extracts. These findings indicate that statements suggesting a hierarchical order of catechin content among tea types are inconclusive and should be made with attention to a sampling strategy that specifies the tea subtype and its source. Certain white teas have comparable quantities of total catechins to some green teas, but lesser antioxidant capacity, suggesting that white teas have fewer non-catechin antioxidants present.
\end{abstract}

Keywords: antioxidant, Camellia sinensis, catechins, green tea, white tea

Practical Application: In this investigation white and green teas were extracted in ways that mimic common tea preparation practices, and their chemical profiles were determined using validated analytical chemistry methods. The results suggest certain green and white tea types have comparable levels of catechins with potential health promoting qualities. Specifically, the polyphenolic content of green teas was found to be similar to certain white tea varieties, which makes the latter tea type a potential substitute for people interested in consuming polyphenols for health reasons. Moreover, this study is among the first to demonstrate the effect subtype sampling, source of procurement, cultivation, and processing practices have on the final white tea product, as such analysis has previously been mostly carried out on green teas.

\section{Introduction}

Tea from the young buds and leaves of Camellia sinensis (L.) O. Kuntze (Theaceae) is the most widely consumed beverage in the world following water and is valued for its taste, aroma, health benefits, and cultural practices (Khokhar and Magnusdottir 2002). The tea plant is considered native to southwestern China and is cultivated in tropical regions globally (Pettigrew 2004). White, green, oolong, black, and pu'erh teas are the major tea types sourced from leaves and buds of the tea plant and are categorized

MS 20100234 Submitted 3/3/2010, Accepted 5/4/2010. Authors Unachukwu, Kavalier, Lyles, and Kennelly are with Dept. of Biological Sciences, Lehman College, Bronx, NY 10468, U.S.A. Authors Unachukwu, Ahmed, and Kennelly are with Ph.D. Programs in Biochemistry, The Graduate Center, City Univ. of New York, 365 Fifth Ave., NY 10016, U.S.A. Authors Ahmed, Kavalier, Lyles, and Kennelly are also with Biology, The Graduate Center, City Univ. of New York, 365 Fifth Ave., NY 10016, U.S.A. Author Ahmed is also with Inst. of Economic Botany, The New York Botanical Garden, Bronx, NY 10458, U.S.A. Direct inquiries to author Kennelly (E-mail: edward.kennelly@lehman.cuny.edu). based on variation in harvesting, processing, and associated degree of oxidation of polyphenols in fresh tea leaves (Pettigrew 2004). These tea types also differ based on the variety of Camellia sinensis used in their production. For instance, Chinese and Japanese green teas are made from Camellia sinensis var sinensis while black teas are made from Camellia sinensis var assamica (Takeo 1992). Of all these tea types, white teas are less known in western communities but a valued tea in Asia; its flavor is even more accepted than that of green tea in Europe (Almajano and others 2008).

White teas have been reported to possess higher antielastase, anticollagenase, and antioxidative activity than certain green tea, suggesting its ability to promote strong and elastic skin and alleviate inflammation and rheumatoid arthritis, has led to an increased interest in this tea type (Thring and others 2009). White tea lipolytic activity and its ability to inhibit adipogenesis have received particular attention especially in developed countries battling with dramatic increases in obesity and obesity-related diseases (Sõhle and others 2009).

White teas differ from other tea types by being produced from unopened buds, classified as silver needle (bai hao Yinzhen), or 
incorporating an unopened bud and 2 immature leaves, covered in white leaf hairs, at an early stage of chlorophyll formation, as is the case for white peony (bai mudan) (Pettigrew 2004). To distinguish between green and white tea production processes, mature leaves for green tea production are withered, briefly pan-fried, rolled, and dried in the traditional Chinese green tea making process. Some Chinese tea manufacturers steam rather than pan-fry their tea leaves, much like the Japanese style of green tea production (Pettigrew 2004; Hilal and Engelhardt 2007; Ho and others 2009). Both tea heating methods deactivate the polyphenol oxidase enzymes. In some published reports, some white teas, are also steamed during processing to deactivate enzymes. Most white teas use new buds plucked before they are opened then are withered and air dried in the shade, under sunshine, or in a temperature controlled room to remove moisture content (Pettigrew 2004). The dried buds have a curled silvery appearance.

Some studies support that among all tea types, green teas contain the highest amount of catechins, a group of polyphenolic flavan-3-ol monomers and their gallate derivatives (Lin and others 2003). The major catechins include (-)-epicatechin (EC), (-)epigallocatechin (EGC), (-)-epicatechin-3-gallate (ECG), and (-)-epigallocatechin-3-gallate (EGCG). These compounds are primarily responsible for many of the health protective properties associated with tea including antioxidative (Mildner-Szkudlarz and others 2009), antiinflammatory (Cao and others 2007), neuroprotective (Mandel and Youdim 2004), anti-cancer (Yang and others 2002) antimicrobial, and antiatherosclerotic properties (Zhen 2002). However, other reports suggest that catechin and total phenolic content (TPC) cannot be used as a criterion for differentiating between green and white teas (Hilal and Engelhardt 2007). Chinese white teas have also been reported to possess greater antimutagenic properties than premium green teas (Sanatan-Rios and others 2001; Hilal and Engelhardt 2007) and comparable antioxidant effects as green teas in body plasma and some organs (Koutelidakis and others 2009). White teas have also been found to contain higher amounts of caffeine than green teas (Hilal and Engelhardt 2007) which along with other methylxanthines, such as TB and TP, the amino acid theanine, and free sugars, are compounds commonly found in tea.

Given the numerous factors that affect the end tea product for consumption or laboratory analysis including climate, soil, plucking time, as well as processing and preparation methods (Zhen 2002; Lin and others 2003; Pettigrew 2004) and, the growing role of tea in daily food intake in the United States over the past 2 decades (Sultana and others 2008), the inter-variation of beneficial compounds between green and white teas and intra-variation within each tea type should be recognized. The Camellia sinensis variety used in tea production also determines the amount of these beneficial compounds where for instance, the assamica variety has been reported to possess more than twice the flavanol content of the sinensis variety although its use is restricted to the production of black tea due to the bitter flavor that results from its high flavanol content (Takeo 1992). A literature survey on the chemical profile and bioactivity of all tea types reveals a lack of information or agreement on the nature of white teas in comparison to other tea types while the variation in composition and bioactivity between white and green teas and their subtypes remains unclear (Hilal and Engelhardt 2007). The present study develops and validates an efficient tea extraction and chromatographic method for the quantitative analysis of 9 catechins and 3 methylxanthines in white tea. Previous studies on white teas have treated it as a single product by including only 1 white tea subtype in their sampling protocol (Rusak and others 2008; Horzic and others 2009), or by not specifying the white tea subtypes being investigated (Hilal and Engelhardt 2007).

The present study accounts for possible intra-variation of compounds in white tea subtypes by examining 2 subtypes of white tea from 4 commercial sources and comparing these with 5 subtypes of green tea from 5 commercial sources. The phenolic composition and antioxidant properties of white and green teas are further investigated using the Folin-Ciocalteau (F-C) TPC assay and the 1-1-diphenyl-2-picrylhydrazyl (DPPH) assay, respectively.

\section{Materials and Methods}

\section{Chemicals and reagents}

Solvents for high-performance liquid chromatography (HPLC) analysis include trifluoroacetic acid (Fisher Scientific, Fair Lawn, N.J., U.S.A.), HPLC-grade acetonitrile (J.T. Baker, Phillipsburg, N.J., U.S.A.) and water distilled using a Milli-Q system (Millipore Lab., Bedford, Mass., U.S.A.). HPLC-grade methanol (E. Merck, Darmstadt, Germany) was used for sample preparation. Reagent-grade ethanol (Fisher Scientific), ascorbic acid, and 11-diphenyl-2-picrylhydrazyl (DPPH, Sigma Chemical Co., St. Louis, Mo., U.S.A.) were used for the DPPH scavenging assay. F-C reagent $(2 \mathrm{~N})$ and sodium carbonate powder ( $>99.5 \%$ purity) (Sigma Chemical Co.) were used for the TPC assay.

\section{Standards}

Pure standards of gallic acid (GA) (1), (+)-catechin (C) (2), caffeine (CAF) (3), (-)-epigallocatechin 3-gallate (EGCG) (4), and (-)-gallocatechin (GC) (5) were purchased from ChromaDex (Santa Ana, Calif., U.S.A.). (-)-Epicatechin 3-gallate (ECG) (6), (-)-epigallocatechin (EGC) (7), and (-)-catechin 3-gallate (CG) (8) were purchased from Fisher Scientific (Pittsburgh, Pa., U.S.A.). Theobromine (TB) (9), theophylline (TP) (10), (-)-gallocatechin 3-gallate (GCG) (11) and (-)-epicatechin (EC) (12) were obtained from Sigma Chemical Co. Quercetin dihydrate (Sigma Chemical Co.) was used as an internal standard for calibration purposes.

\section{Plant materials}

A total of 8 samples of white teas of 2 major subtypes, white peony (bai mudan) and Yin Zhen silver needle (bai hao Yin Zhen), both from the Fujian Province in China (Pettigrew 2004), and 19 samples of green tea representing 5 subtypes (dragonwell, gunpowder, jasmine pearl, sencha, and gykuro) were obtained from 5 commercial companies-A,B,C,D, and E. Loose leaf tea samples were utilized for all experiments because extraction of compounds from loose leaf teas have been shown to be more effective than bagged teas in quantification of analytes (Rusak and others 2008). All tea sample analysis was carried out in triplicate.

\section{Sample extraction}

Water and aqueous methanol extracts of tea were prepared for quantification of phenolic and methylxanthine composition and bioactivity. Tea water extraction procedures replicated preparation conditions of cosmopolitan tea drinking (Khokhar and Magnusdottir 2002; Rusak and others 2008). Dry tea leaves (1 g) were steeped in $100 \mathrm{~mL}$ of deionized water at 95 to $100{ }^{\circ} \mathrm{C}$ for $5 \mathrm{~min}$. The resultant tea mixture was filtered under vacuum using Whatman nr 5 filter paper. An aliquot $(1.5 \mathrm{~mL})$ of the filtrate was centrifuged at $15000 \mathrm{rpm}$ for $15 \mathrm{~min}$ and the supernatant was passed through a $0.45 \mu \mathrm{m}$ nylon membrane filter prior to HPLC analysis. The remainder of the filtrate was frozen at $-20^{\circ} \mathrm{C}$ and 
freeze-dried in a lyophilizer to obtain dried water extracts for DPPH and TPC assays.

Alcohol extraction was carried out to mimic industrial and research conditions (Rusak and others 2008). Methanol extracts were obtained using a modification of the procedure previously described (Nuntanakorn and others 2007). Ground dry tea leaves were extracted with $80 \%$ aqueous methanol in a ratio of $1 \mathrm{~g}: 10 \mathrm{~mL}$ solvent $(\mathrm{w} / \mathrm{v})$ using a sonicator for $30 \mathrm{~min}$. The supernatant was filtered under vacuum using Whatman $\mathrm{nr} 5$ filter paper and the filtrate was centrifuged at $15000 \mathrm{rpm}$ for $15 \mathrm{~min}$ and filtered through a $0.45 \mu \mathrm{m}$ nylon membrane filter after pre-flushing with the sample prior to HPLC analysis.

\section{High-performance liquid chromatography (HPLC)}

HPLC analysis was performed using a Waters 2695 HPLC (Milford, Mass., U.S.A.) module equipped with a 996 photodiode array detector (PDA) and operated with Empower software. Samples and standards were separated on a Synergi Fusion, $4 \mu \mathrm{m}, 250 \times$ $4.6 \mathrm{~mm}$ ID, C-18 reversed-phase column (Phenomenex, Torrance, Calif., U.S.A.). Column temperature was maintained at $30{ }^{\circ} \mathrm{C}$ with a column heater and the autosampler temperature at $4{ }^{\circ} \mathrm{C}$. A gradient system was used for the mobile phase comprising $0.05 \%(\mathrm{v} / \mathrm{v})$ trifluoroacetic acid in distilled water $(\mathrm{A})$ and in acetonitrile (B), with a flow rate of $1 \mathrm{~mL} / \mathrm{min}$ and duration of $35 \mathrm{~min}$. The gradient profile employed was as previously described (Dalluge and others 1998) and is as follows: 0 to $25 \mathrm{~min}, 12 \%$ to $21 \% \mathrm{~B} ; 25$ to $30 \mathrm{~min}, 21 \%$ to $25 \% \mathrm{~B}$. The column was flushed with $100 \% \mathrm{~B}$ for $10 \mathrm{~min}$ and re-equilibrated for $5 \mathrm{~min}$ to starting conditions. Sample volume injected was $5 \mu \mathrm{L}$ for methanol extracts and $40 \mu \mathrm{L}$ for water extracts. The UV-vis spectra were recorded from 254 to $400 \mathrm{~nm}$ and relevant peaks were detected at $280 \mathrm{~nm}$. Peaks were identified based on characteristic absorbance spectra and retention time.

\section{Validation of HPLC method}

Validation was carried out in compliance with the AOAC Intl. Guidelines for Single Lab. Validation of Chemical Methods for Dietary Supplements and Botanicals (AOAC 2002). The method was validated with respect to selectivity, linearity, recovery, detection, and quantification limits and precision.

Calibration curves were established on 5 to 7 data points for serial dilutions of standards 1 to 12 using 80\% methanol, measured at $280 \mathrm{~nm}$ and covering a concentration range of 2.23 to $11000 \mu \mathrm{g} / \mathrm{mL}$. Recovery studies were conducted by spiking loose leaf tea leaves with $0.985,1.97$, and $3.94 \mathrm{mg} / \mathrm{mL}$ concentrations of quercetin dihydrate $\left(3,3^{\prime}, 4^{\prime}, 5,7\right.$-pentahydroxyflavone) used as an internal standard.

For intra-day assay, 10 replicate analyses of standards 1, 4 to 12 was carried out and was also performed at 2 different concentrations $(0.6$ and $1 \mathrm{mg} / \mathrm{mL})$ of the mixture of 10 standards on 2 different days for inter-day precision studies. Precision at each concentration was expressed as \% RSD of measured peak areas from mean peak area. Peak resolution $\left(\mathrm{R}_{\mathrm{s}}\right)$ was calculated as the ratio of the difference in retention times $\left(\mathrm{T}_{1 \& 2}\right)$ between adjacent peaks to the summation of peak bandwidths at half height $\left(\mathrm{W}_{0.5,1 \& 2}\right)$ according to the formula below (Snyder and others 1997):

$$
\mathrm{Rs}=1.18\left(T_{2}-T_{1}\right) / W_{0.5,1}+W_{0.5,2}
$$

Dilutions of standards 1 to 4, 6, 9, and 10 were analyzed by HPLC to obtain concentrations with peak signal-to-noise ratio of about $3: 1$ (limit of detection [LOD]) and 10:1 (LOQ).
Results were expressed as detectable or quantifiable concentrations in micrograms per milliliter.

\section{1-1-Diphenyl-2-picrylhydrazyl (DPPH) radical scavenging assay}

The DPPH radical scavenging assay was performed as previously described (Saito and others 2007b). Dissolved tea water extracts $(50 \mu \mathrm{L})$ were mixed with $150 \mu \mathrm{L}$ of $400 \mu \mathrm{M}$ DPPH solution. The mixtures were incubated for $30 \mathrm{~min}$ at $37^{\circ} \mathrm{C}$ and absorbance values were measured at $517 \mathrm{~nm}$ using a Softmax Pro 3.0 microplate reader (Molecular Devices, Sunnyvale, Calif., U.S.A.). Radical scavenging ability of samples was calculated as the percentage of DPPH free radicals inhibited by samples in comparison to radical inhibition in the negative water control used:

$$
\left(\mathrm{ABS}_{\text {negative control }}-\mathrm{ABS}_{\text {sample }} / \mathrm{ABS}_{\text {negative control }}\right) * 100
$$

Gallic acid $(0.015625$ to $0.25 \mathrm{mg} / \mathrm{mL})$ and ascorbic acid $(0.03125$ to $0.5 \mathrm{mg} / \mathrm{mL})$ were used as positive controls. Values obtained were plotted against concentration $(\mu \mathrm{g} / \mathrm{mL})$ of sample dilutions and final results are expressed as $\mathrm{IC}_{50}$ values (concentration of samples required to scavenge $50 \%$ of DPPH radicals).

\section{Total phenolic content (TPC) assay}

TPC was determined spectrophotometrically using $\mathrm{F}-\mathrm{C}$ reagent as previously described (Prior and others 2005). To $100 \mu \mathrm{L}$ of dilutions of tea water extracts was added $1 \mathrm{~mL}$ of $10 \%(\mathrm{v} / \mathrm{v}) 2 \mathrm{~N}$ $\mathrm{F}-\mathrm{C}$ reagent and after incubation at room temperature for $5 \mathrm{~min}$, $1 \mathrm{~mL}$ of $10 \%(\mathrm{~m} / \mathrm{v})$ sodium carbonate solution was added to make extracts alkaline. Mixtures were incubated for $90 \mathrm{~min}$ at room temperature after which absorbance was measured at $765 \mathrm{~nm}$ and results expressed as gallic acid equivalents (GAE) in milligram per gram dry plant material. The concentration of polyphenols in samples was derived from a standard curve of absorbance of gallic acid concentrations ranging from 31.25 to $500 \mu \mathrm{g} / \mathrm{mL}$.

\section{Statistical analysis}

Results were analyzed statistically using JMP 7.0 software (SAS) to determine mean values, standard deviations and standard error of means of quantified masses of compounds analyzed by HPLC in triplicates. ANOVA with a significance level of $\alpha=0.05 \%$ was performed to determine the relationship between tea type and total catechins, individual catechins, $\mathrm{IC}_{50}$ antioxidant activity, and TPC. Differences with $P \leq 0.05$ were considered significant. Total catechin content (TCC) for water and methanol extracts was resolved by the addition of the amounts of individual catechins (EGCG, ECG, EGC, GCG, CG, C, and EC). Similar calculations have been assumed by previous analytical studies of tea samples (Khokhar and Magnusdottir 2002; Rusak and others 2008). Correlation analysis was carried out for $\mathrm{DPPH} \mathrm{IC}_{50}$ against $\mathrm{TPC}$, TCC against DPPH $\mathrm{IC}_{50}$, and TCC against TPC to evaluate relationships between both quantities in tea extracts analyzed. Graphs were constructed using JMP 7.

\section{Results and Discussion}

\section{HPLC validation}

The modification of the analytical method separated a mixture of standards of caffeine, gallic acid, and eight catechins (EGC, EC, EGCG, GCG, (+)-C, CG, GC, and ECG) within $22 \mathrm{~min}$. A different column type (Synergi Fusion, Phenomenex, Torrance, Calif., U.S.A.), with similar characteristics as the column (Zorbax 
Eclipse XDB-C18, Rockland Technologies Inc./Dupont, Newport, Del., U.S.A.) utilized by Dalluge and his colleagues enabled the separation of 5 more compounds compared to the 7 compounds (6 phenolics and caffeine) obtained by these researchers (Dalluge and others 1998). Figure 1 shows chromatograms of some white and green tea samples used in this investigation.

Separation of standards was achieved by HPLC with a critical band pair value (Rs. $=3.81)$ calculated as previously described (Sharma and others 2005). Good linearity was observed for all catechins and gallic acid $\left(r^{2}>0.99\right)$ in the given concentra-

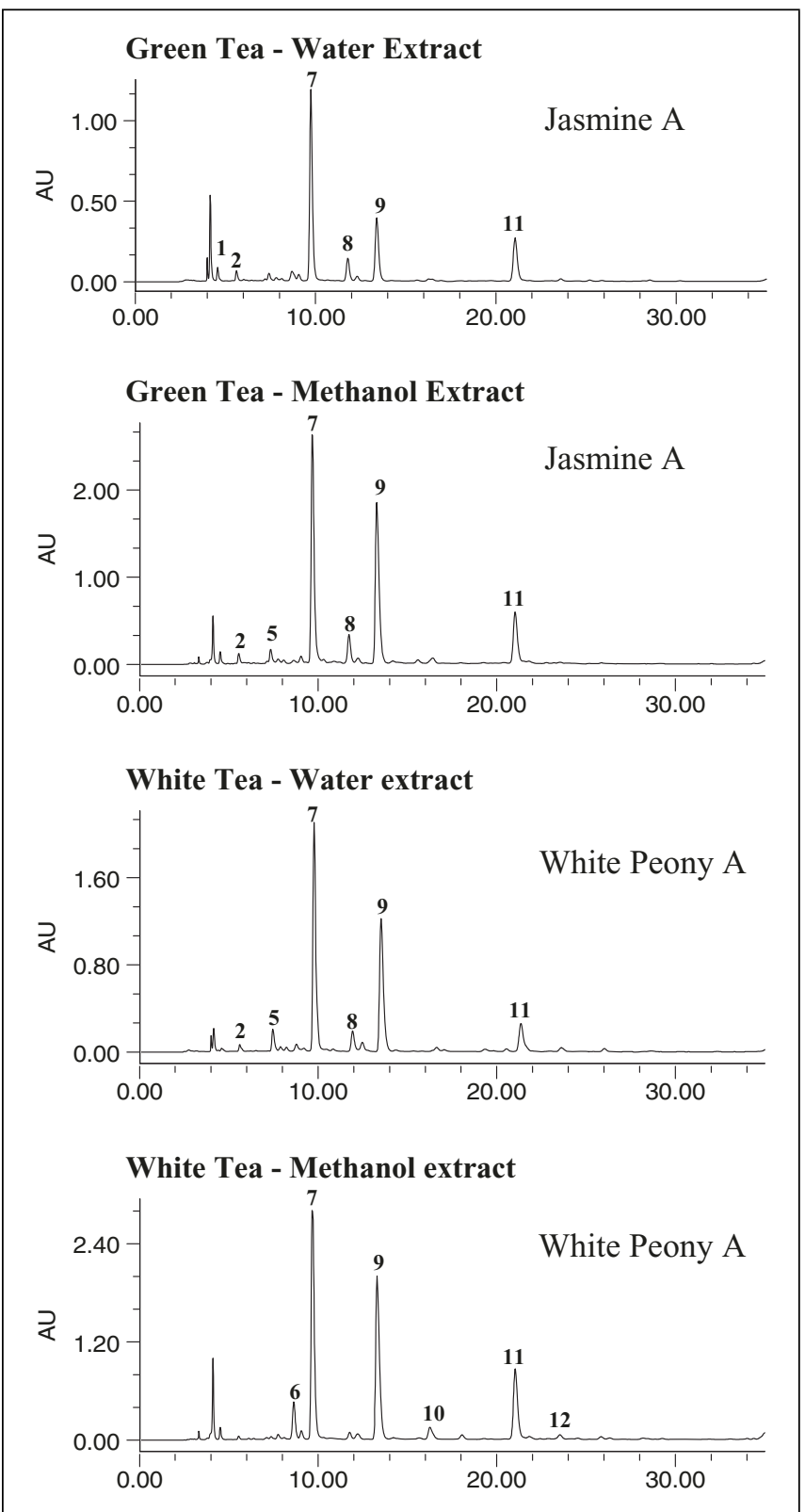

Figure 1-Sampled chromatograms of some white and green teas analyzed using Synergi Fusion $C_{18}$ reverse phase HPLC column $4 \mu \mathrm{m}, 250 \times 4.6 \mathrm{~mm}$ ID by gradient elution as described in Materials and Methods. Detection was carried out with $U V$ at $A_{280}$. Sample source companies are denoted with alphabets $A$ to $D$. Peak identification and approximate retention times in minutes in parentheses are as follows: 1. GA $(4.60 \pm 0.28) ; 2$. TB $(5.45 \pm$ $0.11)$; 3. GC (6.28 \pm 0.025$)$; 4. TP $(6.71 \pm 0.134) ; 5$. EGC (7.66 \pm 0.69$)$; 6. C $(9.64 \pm 0.87) ; 7 . \operatorname{CAF}(9.80 \pm 0.19) ; 8$. EC $(12.34 \pm 0.74) ; 9$. EGCG $(14.30 \pm 1.31) ; 10$. GCG $(16.92 \pm 1.70) ; 11$. ECG $(22.42 \pm 2.04)$; and 12 . CG $(24.69 \pm 2.10)$. tion range except for caffeine whose lower correlation coefficient $\left(r^{2}=0.9787\right)$ was due to optimization of the linear range to account for higher concentrations observed for caffeine in some tea water extract samples. The LOD and the limit of quantification (LOQ) of 7 standards; GA, C, CAF, EGCG, ECG, TP, and TB were found to be in the ranges of 0.05 to $1 \mu \mathrm{g} / \mathrm{mL}$ and 0.1 to $5 \mu \mathrm{g} / \mathrm{mL}$, respectively.

Intra-day analysis of a standard mixture of 10 compounds containing GA, GCG, CG, EGCG, GC, ECG, EGC, TB, TP, and EC ranged between $0.19 \%$ and $0.53 \%$ for repeatability precision experiments, while inter-day analysis of the same standard mix in 2 concentration levels $(0.6$ and $1 \mathrm{mg} / \mathrm{mL})$ over 2 different days yielded \% RSD percent ranging from $0.13 \%$ to $1 \%$ for $0.6 \mathrm{mg} / \mathrm{mL}$ concentrations, and $0.1 \%$ to $1.07 \%$ for $1 \mathrm{mg} / \mathrm{mL}$ concentrations. Percent recovery of internal standard, quercetin dihydrate $\left(r^{2}=0.9996\right)$, using an extraction method modified from the published procedure (Nuntanakorn and others 2007; see Appendix 1) ranged from $64.2 \%$ to $93 \%$ for green teas and $81.6 \%$ to $101.7 \%$ for black teas (see Appendix 2).

\section{Comparing total catechin content (TCC) of white and green teas}

TCC results show inter- and intra-variation in tea types and subtypes as well as with the type of extraction method employed. TCC for white tea methanol extracts ranged from 47.16 to $169.94 \mathrm{mg} / \mathrm{g}$ and from 32.23 to $141.24 \mathrm{mg} / \mathrm{g}$ for green tea methanol extracts (Table 1). These values constituted mean percent weight of dried plant material of $6.77 \%$ for green teas and $7.62 \%$ for white teas. These results are in accordance with values obtained in previous studies using similar extraction methods and solvents on green teas (Sharma and others 2005). White tea catechin content was higher than green teas with a mean value of $76.15 \mathrm{mg} / \mathrm{g}$ dry tea material (Table 1 ).

TCC for white tea water extracts analyzed ranged more than 25-fold (14.40 to $369.60 \mathrm{mg} / \mathrm{g}$ dry plant material; Table 1) and had about an 11-fold range (21.38 to $228.20 \mathrm{mg} / \mathrm{g}$ ) for green teas. Mean total catechins of water extracts constituted $8.20 \%$ of dry loose-leaf white teas and $9.97 \%$ for green teas. Fluctuations in retention times and co-elution between $\mathrm{TB}$ and $\mathrm{GC}$ necessitated an exclusion of these 2 compounds from quantification to avoid systematic errors. TP was not detected in any of the tea samples and was also excluded from calculations as was the case in several other investigations of green teas (Khokhar and Magnusdottir 2002; Sharma and others 2005).

While green tea water extracts had a higher mean total catechin composition of $99.66 \mathrm{mg} / \mathrm{g}$ (Table 1), certain subtypes of white tea possessed higher TCC than green tea subtypes. For instance, Company A's white peony possessed a TCC of $369.60 \mathrm{mg} / \mathrm{g}$ dry leaf water extract and Company C's silver needle yielded $163.94 \mathrm{mg} / \mathrm{g}$ TCC for tea methanol extracts. The highest green tea TCC was observed for company E's green tea water extract with a quantity of $228.20 \mathrm{mg} / \mathrm{g}$ dry tea. However, white peony samples from other companies contained significantly lower catechin content, making statements regarding the tea subtype with higher catechin content inconclusive (Table 1).

Rusak and others (2008) have previously reported that green teas have significantly higher amounts of phenolics and flavonoids in the first $5 \mathrm{~min}$ of extraction as compared to white teas when both water and aqueous methanol solvents are used for extraction. The lipophilic cell wall of trichomes on white tea buds appear to affect the extraction kinetics of hydrophilic catechins (Rusak and others 2008). Conversely, Hilal and Engelhardt (2007) found 
higher mean levels of total catechins in white teas than in green tea samples analyzed. In the present study, higher levels of catechins in some white tea samples and variation among samples of a particular subtype from different commercial sources shows that categorical statements regarding the relative quantities of catechins in green and white teas should be made with considerations to the specific subtype and source of tea analyzed as has been previously noted (Friedman and others 2006). Additionally, in a one-way ANOVA among tea types for TCC, there was no significant difference between green and white teas in their water $\left(F_{1,79}=0.72\right.$, $P=0.4004)$ and methanol extracts $\left(F_{1,79}=1.38, P=0.2437\right)$ for TCC, further making hierarchical statements of catechin content between both tea types questionable (see Appendixes 3 and 4).

\section{Comparing levels of individual catechins, caffeine,} and gallic acid in white and green teas

Comparison of the quantified catechin and methylxanthine profile of white and green tea methanol and water extracts are provided in Figure 2 and 3 respectively. EGCG had the highest mean value of all catechins quantified in both green and white teas. This compound did not vary significantly in quantity between white and green tea types in their methanol extracts $(P=0.63)$ and water extracts $(P=0.18)$ (see Appendixes 5 and 6 ).

In the few quantification studies involving both white and green teas, green teas have been reported to be a richer source of phenolics than white teas (Rusak and others 2008; Horzic and others 2009). The limited studies on white tea have mostly based their conclusions on results of analysis of few tea samples and without regard to tea subtype (Hilal and Engelhardt 2007). In the present study, white tea methanol extracts yielded significantly higher mean levels of ECG, C, GCG, and gallic acid $(P<0.0001)$ and relatively higher amounts of EGC and GCG in their water extracts than green teas. White teas also contained higher mean caffeine levels than green teas although the difference was not statistically significant (see Appendixes 5 and 6). Caffeine levels are similar to those published by Saito and others (2007a), using similar extraction solvents. Khokhar and Magnusdottir (2002) reported green teas extracted using aqueous methanol contained caffeine in the range 11 to $20 \mathrm{mg} / \mathrm{g}$, a range covering the amount obtained in this study.

Quantitative analysis of teas reveals strikingly different amounts of most catechins among tea subtypes within the same tea group. For instance, water extracts of certain green teas such as Company D's sencha, Company A's gunpowder and sencha, Company E's green tea, and Company B's gyokuro possessed distinctively high amounts of caffeine, EGCG, and EGC. Most of the white peony subtypes and Company B's silver needle yielded high amounts of EGC and EGCG (see Appendix 7). Methanol extracts of both tea types revealed far less variation among tea subtypes in their catechin and caffeine content. However, certain subtypes as Company C's dragonwell green tea and silver needle white tea, and Company E's jasmine green tea, also possessed distinctively high amounts of EGC, EGCG and ECG (see Appendix 8). These results reveal the individualistic nature of chemical profiles of tea subtypes and make it imperative that further conclusions regarding the comparative amounts of phenolic compounds between green and white teas be made with caution. Khokhar and Magnusdottir (2002) had earlier cited variations in the abundance of compounds in teas as being

Table 1-TCC (mg/g, dry weight) of green and white tea types and sub-types sourced from 5 major tea companies quantified by HPLC-PDA.

\begin{tabular}{|c|c|c|c|}
\hline Tea company & Tea types and sub-types & $\begin{array}{c}\mathrm{TCC}^{\mathrm{a}}-\text { water extracts } \\
\text { mass }(\mathrm{mg} / \mathrm{g} \text { dry tea } \pm \mathrm{SD})^{\mathrm{b}}\end{array}$ & $\begin{array}{c}\text { TCC }^{\mathrm{a}}-\text { methanol extracts } \\
\text { mass }(\mathrm{mg} / \mathrm{g} \text { dry tea } \pm \mathrm{SD})^{\mathrm{b}}\end{array}$ \\
\hline & Green teas & & \\
\hline A & Jasmine Pearl & $28.24 \pm 0.11$ & $51.21 \pm 0.23$ \\
\hline A & Gunpowder & $80.70 \pm 0.08$ & $61.05 \pm 0.34$ \\
\hline $\mathrm{C}$ & Gunpowder & $37.73 \pm 3.81$ & $59.41 \pm 0.31$ \\
\hline $\mathrm{B}$ & Gunpowder & $94.74 \pm 0.16$ & $32.23 \pm 0.34$ \\
\hline $\mathrm{E}$ & Gunpowder & $188.37 \pm 0.44$ & $46.21 \pm 0.33$ \\
\hline A & Gyokuro & $34.03 \pm 0.11$ & $52.55 \pm 0.14$ \\
\hline A & Sencha & $166.44 \pm 0.61$ & $47.54 \pm 0.18$ \\
\hline $\mathrm{C}$ & Sencha Overture & $40.71 \pm 5.72$ & $74.50 \pm 0.67$ \\
\hline $\mathrm{C}$ & Gyokuro & $78.39 \pm 9.34$ & $67.47 \pm 0.48$ \\
\hline $\mathrm{C}$ & Dragonwell & $86.82 \pm 4.96$ & $91.72 \pm 7.30$ \\
\hline $\mathrm{D}$ & Gyokuro & $80.75 \pm 16.79$ & $57.05 \pm 0.31$ \\
\hline $\mathrm{D}$ & Jasmine Pearls & $21.38 \pm 0.21$ & $74.24 \pm 0.30$ \\
\hline $\mathrm{D}$ & Sencha & $161.74 \pm 2.40$ & $73.19 \pm 0.66$ \\
\hline $\mathrm{B}$ & Gyokuro & $179.35 \pm 0.20$ & $36.90 \pm 0.22$ \\
\hline $\mathrm{B}$ & Dragonwell & $175.01 \pm 0.29$ & $63.18 \pm 0.46$ \\
\hline $\mathrm{B}$ & Jasmine Green & $142.74 \pm 0.19$ & $57.16 \pm 0.25$ \\
\hline $\mathrm{E}$ & Jasmine & $149.37 \pm 1.97$ & $123.42 \pm 3.76$ \\
\hline \multirow[t]{3}{*}{$\mathrm{E}$} & Green Tea & $228.20 \pm 3.32$ & $141.24 \pm 6.60$ \\
\hline & Mean $\pm \mathrm{SE}(\mathrm{mg} / \mathrm{g})$ & $109.71 \pm 3.00$ & $67.23 \pm 1.54$ \\
\hline & White Teas & & \\
\hline A & Silver Needle & $48.04 \pm 0.53$ & $76.69 \pm 0.59$ \\
\hline A & White Peony & $369.60 \pm 0.16$ & $47.16 \pm 0.12$ \\
\hline $\mathrm{C}$ & Silver Needle & $14.40 \pm 4.49$ & $163.94 \pm 0.55$ \\
\hline $\mathrm{C}$ & White Peony & $39.27 \pm 0.65$ & $71.37 \pm 0.15$ \\
\hline $\mathrm{D}$ & Yinzhen Silver Needle & $15.24 \pm 0.13$ & $49.17 \pm 0.10$ \\
\hline $\mathrm{D}$ & White Peony & $35.50 \pm 0.13$ & $64.42 \pm 0.60$ \\
\hline $\mathrm{B}$ & Silver Needle & $62.29 \pm 0.17$ & $72.75 \pm 0.66$ \\
\hline \multirow[t]{2}{*}{$\mathrm{B}$} & White Peony & $89.64 \pm 0.03$ & $69.99 \pm 0.28$ \\
\hline & Mean $\pm \mathrm{SE}(\mathrm{mg} / \mathrm{g})$ & $82.01 \pm 12.73$ & $76.15 \pm 5.61$ \\
\hline
\end{tabular}

$\mathrm{NP}=$ not performed.

${ }^{\text {a TCC }}$ is computed by adding means of 7 catechins-EGC, C, EC, EGCG, GCG, ECG, CG.

${ }^{\mathrm{b}}$ Mean and standard deviation (SD) of triplicate HPLC injections. 
dependent on sample tea subtypes and the different subtypes result from different tea processing protocols, horticultural practices, and geographic settings (Pettigrew 2004; Sultana and others 2008).

Teas from 5 different companies were used in this investigation, and similar tea subtypes possessed varied quantities of phenolics and caffeine depending on the tea company source. For instance, TCC of water extracts of white peony white tea subtype produced by 3 different companies; A, B, and D are 369.6, 89.64, and $35.5 \mathrm{mg} / \mathrm{g}$, respectively, although their catechin content yield in methanol extracts did not vary greatly. Gunpowder green tea subtype from Companies B and E yielded 94.74 and $188.37 \mathrm{mg} / \mathrm{g}$ in tea water extracts, and 32.23 and $46.21 \mathrm{mg} / \mathrm{g}$, respectively in their methanol extracts (Table 1). Variation in phytochemical composition among samples of a particular tea subtype from different commercial sources may be the result of storage conditions and storage duration (Friedman and others 2008). Some manufactures follow protocols to ensure freshness of their tea products while other manufacturers store their tea products for extended periods with less attention to optimal storage conditions; the latter practice likely resulting in degradation of phytochemical composition (Friedman and others 2008).
Results from this study support that solvent, extraction protocols, and the source of tea procurement yields variations in the relative amount of compounds in teas. As such, it is suggested that investigations into the chemical profile of teas should follow sampling protocols that include tea samples from various sources and manufacturers and be accompanied with tea subtype specifications, a practice already being adopted by some researchers (Saito and others 2007b; Lin and others 2008).

\section{Phenolic content and antioxidant activity}

\section{of white and green teas}

White teas yielded mean DPPH IC $_{50}$ values of $36.07 \mu \mathrm{g} / \mathrm{mL}$ while green teas exhibited significantly $(P=0.0002)$ higher antioxidant activity with $\mathrm{IC}_{50}$ values of $23.26 \mu \mathrm{g} / \mathrm{mL}$ (Figure 4). Gallic and ascorbic acids were used as positive controls resolving scavenging activity with mean $\mathrm{IC}_{50}$ values of $3.68 \mu \mathrm{g} / \mathrm{mL}\left(r^{2}=\right.$ $0.9943)$ and $11.56 \mu \mathrm{g} / \mathrm{mL}\left(r^{2}=0.9998\right)$ respectively. Comparable DPPH results from investigations by Saito and others (2007b) on green teas have $\mathrm{IC}_{50}$ values ranging from 8.33 to $16.10 \mu \mathrm{g} / \mathrm{mL}$, values slightly lower than obtained in our investigation; however, the tea extraction methods differ. Manian and
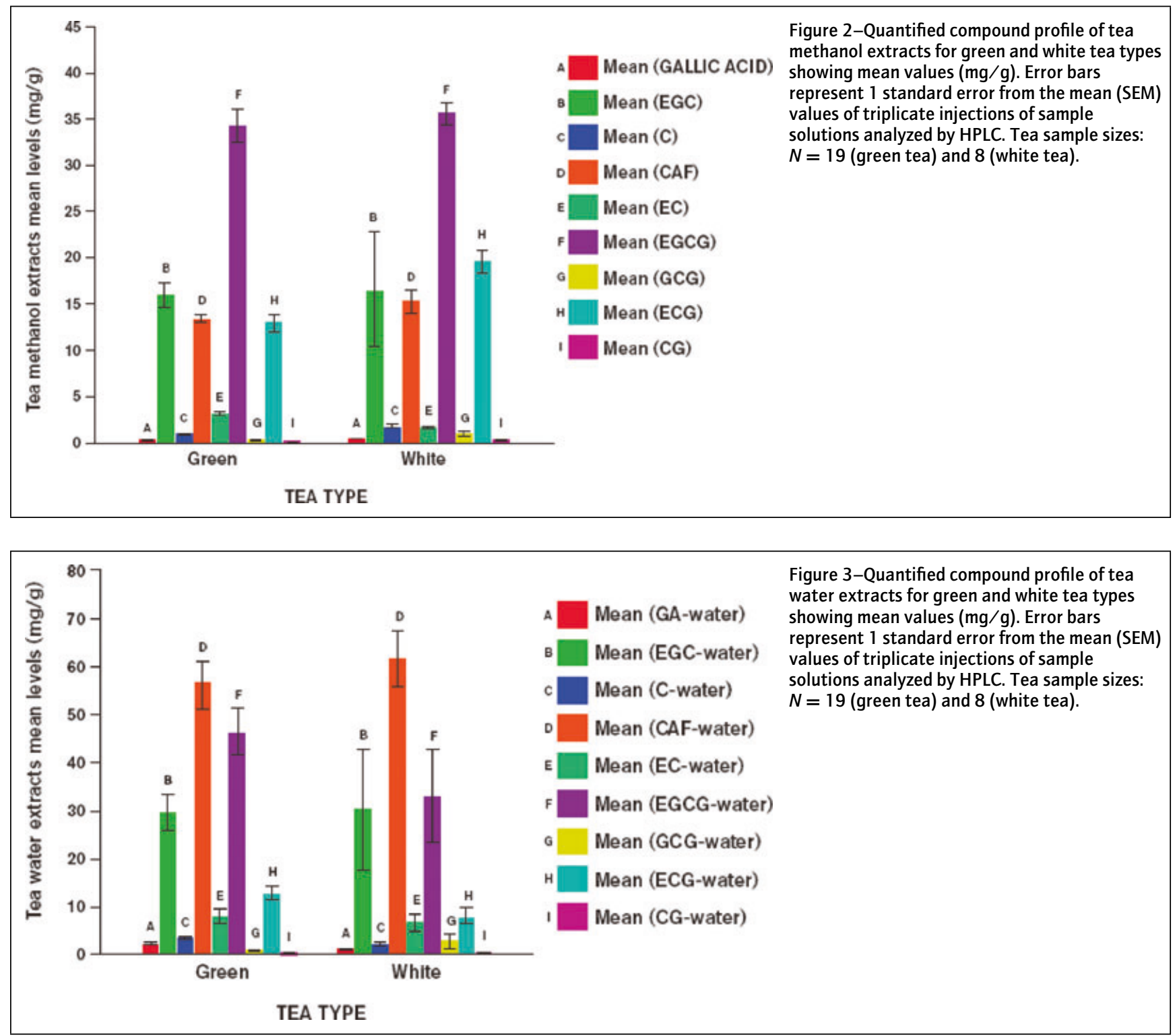
others (2008) observed DPPH IC 50 values for green tea extracts of $19.50 \mu \mathrm{g} / \mathrm{mL}$ with a slightly different extraction method. Green teas also possessed significantly $(P<0.0001)$ higher mean TPC (7.72 mg GAE/g dry tea) than white teas (3.42 mg GAE/g dry tea) (Figure 5). Green tea TPC values range from 1.17 to $18.59 \mathrm{mg}$ GAE/g while the range for white tea TPC was 0.96 to $5.62 \mathrm{mg}$ GAE/g. Rusak and others (2008) reported white tea phenolic content values in the range of 0.4 to $2.1 \mathrm{mg} \mathrm{GAE} / \mathrm{g}$ although the acid hydrolysis procedure and the varying solvents employed in their sample extraction may account for differences with results obtained in this investigation, a trend also observed in their green tea results (0.8 to $2.4 \mathrm{mg} \mathrm{GAE/g).} \mathrm{Khokhar} \mathrm{and} \mathrm{Magnusdottir} \mathrm{(2002)}$ reported higher phenolic content levels for green tea (65.8 to $106.2 \mathrm{mg} / \mathrm{g}$ ) using similar leaf extraction methods as in the present study, but the different values may stem from variations in the $\mathrm{F}-\mathrm{C}$ assay protocols (Prior and others 2005).

Previous researchers have attributed the DPPH scavenging activity of tea principally to the presence of catechins, especially EGCG (Nanjo and others 1999). This study reveals that although white and green tea subtypes have comparable TCC and EGCG

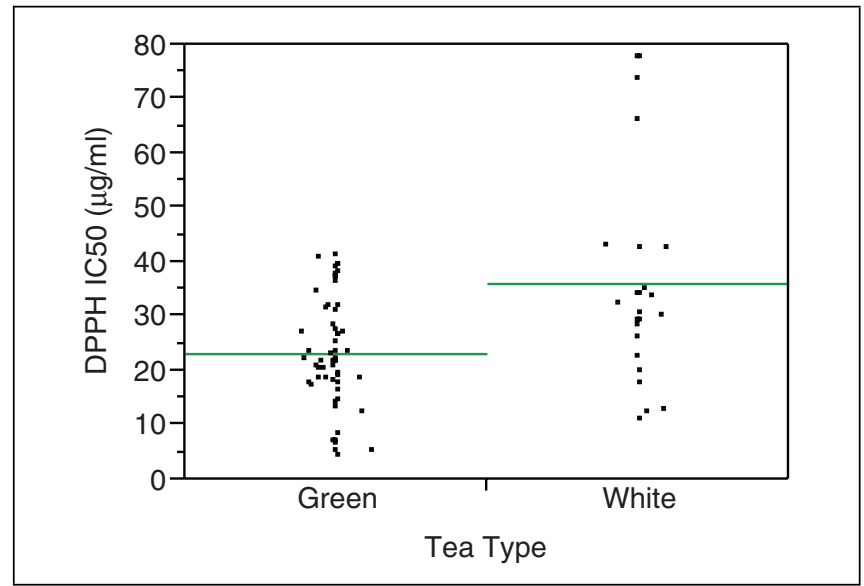

Figure 4-One-way ANOVA for DPPH IC ${ }_{50}$ among tea types extracted using $100{ }^{\circ} \mathrm{C}$ water for $5 \min \left(F_{1,79}=15.21, P=0.0002\right)$. Number of samples $(N)=19$ and 8 for green and white tea samples, respectively. Bars depict mean $\mathrm{IC}_{50}$ values expressed in microgram per milliliter.

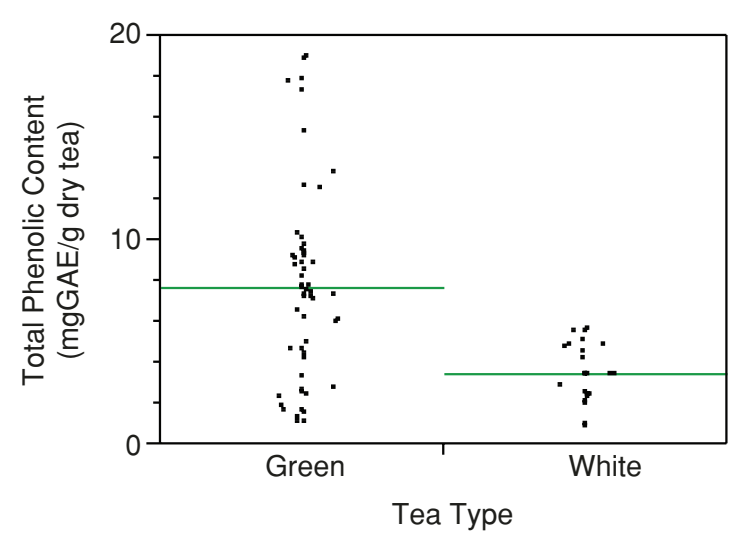

Figure 5-One-way ANOVA for TPC among tea types extracted using $100{ }^{\circ} \mathrm{C}$ water for $5 \min \left(F_{1,79}=19.49, P<0.0001\right)$. Number of samples $(N)=19$ and 8 for green and white tea samples, respectively. Bars depict mean phenolic content values expressed in milligram GAE per gram dry tea. levels, green tea samples possessed significantly higher antioxidant activity. This is likely due to the presence of additional antioxidant compounds such as glycosylated flavonols, proanthocyanidins, and phenolic acids and their derivatives (Lin and others 2008) in green tea as evident by higher TPC levels. According to Lin and others (2008), teas consisting of younger buds and leaves harvested in the early-leaf growing stage (white teas) contained lower levels of these additional phenols than more mature leaves used in tea production (green teas). Further, the researchers reported that hot water infusions of white teas, prepared in a similar way as in this study, would not contain acylated flavonol glycosides, which may result in lower TPC levels and antioxidant activity. Horzic and others (2009) also asserts that the antioxidant capacity of tea is not determined by one or few phytochemical compounds in botanicals, but is widely distributed among a range of phenolics including catechins.

To confirm the phenol-redox assay relationship, a multivariate correlation analysis between DPPH IC $\mathrm{IC}_{50}$ values and TPC $(r=$ -0.3058 ) of white tea water extracts in this study demonstrates the increase in antioxidant activity (lower $\mathrm{IC}_{50}$ values) of the tea samples as their total phenolic strength increases. However, very low positive correlation obtained between TCC of white tea extracts and their DPPH IC 50 values $(r=0.0093)$ and TPC $(r=0.1080)$ shows that catechins are not the only compounds responsible for the redox reactions measured in both assays. In contrast, TPC of green tea water extracts was positively correlated with the TCC $(r=0.6217)$ and negatively correlated with $\mathrm{DPPH} \mathrm{IC}_{50}$ values $(r=-0.4143)$. TCC of green tea water extracts contributed to the radical scavenging abilities of the tea type $(r=-0.4845)$. Correlation values obtained for green teas are similar to results by Saito and others (2007b) (TCC against DPPH; $r=-0.628$ ), although sample extraction systems differ slightly.

\section{Conclusions}

This study provides evidence of the dependability of relative amounts of compounds in tea types on factors involved in the cultivation, processing, handling, and packaging of teas that lead to the commercially available subtypes (Khokhar and Magnusdottir 2002). Present findings support that order ranking of tea types for abundance of constituent compounds such as phenolics or methylxanthines would be valid for comparative purposes only if cultivation and tea processing practices can be controlled. For validity purposes, comparisons widely asserted in many publications of the relative amount of phenolic compounds to be in the order of green $>$ oolong $>$ black $>$ white (Lin and others 1998; Lin and others 2003; Rusak and others 2008) or the order black > oolong $>$ green $>$ white (Khokhar and Magnusdottir 2002; Lin and others 2003) with regards to caffeine content, should be based on a sampling protocol inclusive of a range of subtypes procured from various commercial sources. Certain white tea subtypes such as white peony contained high amounts of catechins and caffeine that varied depending on extraction protocols and commercial source. These subtypes generate interest in other white tea types such as the silver-tipped Sri Lankan cultivars (Pettigrew 2004), in possible comparative yields obtainable when white tea cultivars are analyzed along with other tea types, or if white tea sampling sizes are increased.

\section{Acknowledgments}

The authors would like to thank the following scientists for contribution to this research investigation: Ulyana Munoz-Acuna, Amy Keller, Dr. Bei Jiang, Dr. Hui Yang, Dr. Mario Figueroa, and 
John Vinod. The authors also express their gratitude to In Pursuit of Tea and Adagio tea companies for their tea samples.

\section{References}

Almajano MP, Carbo R, Jimenez JAL, Gordon MH. 2008. Antioxidant and antimicrobial activities of tea infusions. Food Chem 108:55-63.

AOAC. 2002. Guidelines for single laboratory validation of chemical methods for dietary supplements and botanicals. Gaithersburg, Md.: AOAC Int. Available from: http://swww. aoac.org/dietsupp6/Dietary-Supplement-web-site/slv_guidelines.pdf. Accessed Nov 25, 2007.

Cao H, Kelly MA, Kari F, Dawson HD, Urban JF, Coves S, Roussel AM, Anderson RA. 2007. Green tea increases anti-inflammatory tristetraprolin and decreases pro-inflammatory tumor necrosis factor mRNA levels in rats. J Inflam 4:1-12

Dalluge JJ, Nelson BC, Thomas BJ, Sander LC. 1998. Selection of column and gradient elution system for the separation of catechins in green tea using high-performance liquid chromatography. J Chromatogr A 793:265-74.

Friedman M, Levin CE, Choi S, Kozukue E, Kozukue N. 2006. HPLC analysis of catechins, theaflavins and alkaloids in commercial teas and green tea dietary supplements: comparison of water and $80 \%$ ethanol extracts. J Food Sci 71:C328-37.

Friedman M, Levin CE, Lee S, Kozukue N. 2008. Stability of green tea catechins in commercial tea leaves during storage for 6 months. J Food Sci 74:H47-51.

Hilal Y, Engelhardt U. 2007. Characterization of white tea-comparison to green and black tea. J Verbr Lebensm 2:414-7.

Ho C, Lin J, Shahidi F. 2009. White tea: its manufacture, chemistry and health effects. In: Nutraceutical Science and Technology Series 8 . Tea and Tea Products: Chemistry and Health Promoting Properties. Boca Raton, Fla.: CRC Press. p 17-29.

Horzic D, Komes D, Belscak A, Ganic KK, Ivekovic D, Karlovic D. 2009. The composition of polyphenols and methylxanthines in teas and herbal infusions. Food Chem 115:441-8.

Khokhar S, Magnusdottir SGM. 2002. Total phenol, catechin, and caffeine contents of teas commonly consumed in the United Kingdom. J Agric Food Chem 50:565-70.

Koutelidakis AE, Argiri K, Serafini M, Proestos C, Komaitis M, Pecorari M, Kapsokefalou M. 2009. Green tea, white tea, and Pelargonium purpureum increase the antioxidant capacity of plasma and some organs in mice. Nutrition 25:453-8.

Lin J, Lin C, Liang Y, Lin-Shiau S, Juan I. 1998. Survey of catechins, gallic acid and methylxanthines in green, oolong, pu-erh and black teas. J Agric Food Chem 46:3635-42.

Lin L, Chen P, Harnly JM. 2008. New phenolic components and chromatographic profiles of green and fermented teas. J Agric Food Chem 56:8130-40.

Lin Y, Tsai Y, Tsay J, Lin J. 2003. Factors affecting the levels of tea polyphenols and caffeine in tea leaves. J Agric Food Chem 51:1864-73.

Mandel S, Youdim MB. 2004. Catechin polyphenols: neurodegeneration and neuroprotection in neurodegenerative diseases. Free Rad Biol Med 37:304-17.

Manian R, Anusuya N, Siddhuraju P, Manian S. 2008. The antioxidant activity and free radical scavenging potential of two different solvent extracts of Camellia sinensis (L.) O. kuntz, Ficus bengalensis L. and Ficus racemosa L. Food Chem 107:1000-7.

Mildner-Szkudlarz S, Zawirska-Wojtasiak W, Obuchowski W, Golinski M. 2009. Evaluation of antioxidant activity of green tea extract and its effect on the biscuits lipid fraction oxidative stability. J Food Sci 74:S362-70.

Nanjo F, Mori M, Goto K, Hara Y. 1999. Radical scavenging activity of tea catechins and their related compounds. Biosci Biotechnol Biochem 63:1621-3.

Nuntanakorn P, Jiang B, Yang H, Cervantes-Cervantes M, Kronenberg F, Kennelly E. 2007. Analysis of polyphenolic compounds and radical scavenging activity of four American Actaea species. Phytochem Anal 18:219-28.

Pettigrew J. 2004. The tea companion: a connoisseur's guide. 1st ed. Philadelphia, Pa.: Running Press Book Publishers. 160 p.

Prior RL, Wu X, Schiach K. 2005. Standardized methods for determination of antioxidant capacities and phenolics in foods and dietary supplements. J Agric Food Chem 53:4290-302.

Rusak G, Komes D, Likic S, Horzic D, Kovac M. 2008. Phenolic content and antioxidative capacity of green and white tea extracts depending on extraction conditions and the solven used. Food Chem 110:852-58.
Saito ST, Froehlich PE, Gosmann G, Bergold AM. 2007a. Full validation of a simple method for determination of catechins and caffeine in Brazilian green tea (Camellia sinensis var.assamica) using hplc. Chromatographia 65:607-10.

Saito ST, Gosmann G, Saffi J, Presser M, Ritcher FM, Bergold A. 2007b. Characterization of the constituents and antioxidant activity of Brazilian green tea (Camellia sinensis var. assamica IAC-259 cultivar) extracts. J Agric Food Chem 55:9409-14.

Sanatan-Rios G. Orner GA, Amantana A, Provost C, Wu S, Dashwood RH. 2001. Potent antimutagenic activity of white tea in comparison with green tea in salmonella assay. Mutat Res Gene Toxicol Environ Mutagen 495:61-74

Sharma V, Gulati A, Ravindranath SD, Kumar V. 2005. A simple and convenient method for analysis of tea biochemicals by reverse phase HPLC. J Food Comp Anal 18:583-94.

Snyder RL, Kirkland JJ, Glajch JL. 1997. Practical HPLC method development. 2nd ed. Hoboken, N.J.: John Wiley and Sons. 765 p.

Sõhle J, Anja K, Holtzmann U, Siegner R, Grönniger E, Schepky A, Gallinat S, Wenck H, Stäb F, Winnefeld M. 2009. White tea induces lipolytic activity and inhibits adipogenesis in human subcutaneous (pre)-adipocytes. Nutr Metab 6:20.

Sultana T, Stecher G, Mayer R, Trojer L, Qureshi MN, Abel G, Popp M, Bonn KG. 2008. Quality assessment and quantitative analysis of flavonoids from tea samples of different origins by HPLC-DAD-ESI-MS. J Agric Food Chem 56:3444-53.

Takeo T. 1992. Green and semi-fermented teas. In: Wilson KC, Clifford MN, editors. Tea: cultivation and consumption. 1st ed. London. Chapman and Hall. p 413-54.

Thring SAT, Hili P, Naughton DP. 2009. Anti-collagenase, anti-elastase and anti-oxidant activities of extracts from 21 plants. BMC Complement Altern Med 9:27.

Yang CS, Maliakal P, Meng X. 2002. Inhibition of carcinogenesis by tea. Ann Rev Pharmacol Toxicol 42:25-54

Zhen Y. 2002. Tea: green tea, black tea and semi-fermented tea. The chemistry of tea nonvolatiles. Anticarcinogenic activity of tea. In: Cheng S, Chen Z, editors. Tea: bioactivity and therapeutic potential. 1st ed. London: Taylor and Francis. p 35-57.

\section{Appendix}

(1) Table of calibration curves correlation coefficients, limits of detection (LOD) and quantification (LOQ), selectivity, repeatability, and intermediate precision results of standards.

(2) Data of recovery experiments by Internal Standard Method.

(3) One way analysis of variance for total catechins extracted using water solvent, by tea type.

(4) One-way ANOVA for total catechins extracted using methanol by tea type.

(5) Mean distribution and ANOVA results for significant difference among tea types extracted using aqueous methanol.

(6) Mean distribution and ANOVA results for significant difference among tea types extracted using water.

(7) Masses of quantified compounds ( $\mathrm{mg} / \mathrm{g}$, dry weight) in green and white tea types and sub-types obtained using water at $100{ }^{\circ} \mathrm{C}$ and quantified by HPLC-PDA.

(8) Masses of quantified compounds ( $\mathrm{mg} / \mathrm{g}$, dry weight) in green and white tea types and sub-types obtained using aqueous methanol and quantified by HPLC-PDA. 